\title{
Study of the Electromagnetic Interference Generated by Wireless Power Transfer Systems
}

\author{
E. N. Baikova ${ }^{1,3}$, S. S. Valtchev ${ }^{1,2}$, R. Melicio ${ }^{4,5}$, A. Krusteva ${ }^{6}$, V. Fernão Pires ${ }^{3,7}$
}

\begin{abstract}
This paper presents a study related with measuring of radio frequency emissions. The purpose is to determine the level of interference generated by wireless power transfer equipment in a specific frequency range, and to compare those levels to the existing standards. The technology of wireless power transfer, especially for electric vehicles batteries charging, is rapidly developing in the recent years.

An increasing use of this technology in industrial and consumer electronic products has raised concerns about the possible unfavorable health-effects onto the human being. Another concern is raised from the high intensity fields produced by wireless power transfer systems which will generate highly undesired influence on other electrical and electronic equipment. As a protection against the potential health effects, the governments imposed limits on the occupational and general public exposure to the radio frequencies.

These limitations are set out in national and international safety guidelines, standards and regulations. The measurement and evaluation of the human exposure to electromagnetic fields are essential to guarantee occupational and general public safety. Copyright (C) 2016 Praise Worthy Prize S.r.l. - All rights reserved.
\end{abstract}

Keywords: Wireless Power Transfer, Electromagnetic Field Impact, Electromagnetic Field Measurement

\section{Nomenclature}

$V_{S} \quad$ AC power source

$R_{1} \quad$ Primary parasitic resistance

$L_{1} \quad$ Primary inductance

$C_{1} \quad$ Primary capacitance

$L_{M} \quad$ Mutual inductance between the primary and the secondary

$R_{2} \quad$ Secondary parasitic resistance

$L_{2} \quad$ Secondary inductance

$C_{1} \quad$ Secondary capacitance

$R_{L} \quad$ Load resistance

$k_{12} \quad$ Coupling coefficient

$I_{1} \quad$ Primary current

$I_{2} \quad$ Secondary current

$\omega \quad$ Frequency angular

$R_{1}^{\prime} \quad$ Total transmitting circuit resistances

$R_{2}^{\prime} \quad$ Total receiving circuit resistances

$P_{\text {in }} \quad$ Power of the input side

$P_{\text {out }} \quad$ Power of the output side

$\cos \varphi \quad$ Power factor

$\eta$

Power transfer efficiency

\section{Introduction}

The wireless power transfer (WPT) initially introduced by Nikola Tesla, has drawn attention of specialists during last decades [1]-[3].
Nowadays, the WPT is a promising and popular technology among numerous researchers and manufacturers, widely used for industrial and consumer electronic products. The WPT usage is increasing for low power transfer allowing the wireless charging of electronic devices, i.e. mobile phones, laptops, implants and home appliances. The high power equipment such as the industry of intelligent machining systems, robots, the forklift trucks, and electric/hybrid cars are also getting wirelessly powered. Moreover, much attention has been focused on the electric transportation system for improving the safe and convenient charging of the electric vehicles (EV) batteries [1], [4]-[7]. Basically there are two different methods of WPT, defined by physical phenomena of the electromagnetic fields (EMF) propagation: near field and far field. Among the main methods of near field, the inductive coupling, the capacitive coupling and the magnetic resonance coupling can be outlined. The near field methods typically involve the application of the magnetic field and inductive techniques for wireless transmission over relatively short distances, usually much shorter than $1 \mathrm{~m}$, exceptionally reaching up to a few meters. The far field methods allow for long range energy transfer and usually involve radiated electromagnetic energy, including lasers, microwave and radio wave transmissions [8].

The far field methods (microwave and laser power transmission) with directional antennas could be used over long distances for space and military industry or 
industrial applications. However, for consumer applications, such as mobile phones, other portable electronic devices or electric vehicles, the far field methods are not suitable because of efficiency and safety issues. Among the near field methods, the inductive coupling is considered to be a functional and mature technology. However its drawbacks are: a shorter distance operation, a low yield and a need for accurate alignment between the transmitter and receiver coils [1], [9]. The applications based on capacitive coupling are limited by the low transmitted power and the short distance, but they are applicable in the smart card equipment or in small robots [10]. Among the existent near field methods, the best result was achieved by the group of Massachusetts Institute of Technology. The MIT team demonstrated the efficient wireless energy transfer over a mid-range distance of $2 \mathrm{~m}$ between the transmitter and receiver using magnetic resonance [3]-[5].

The magnetic resonance technique is recognized to be the most appropriate when the target is the wireless EV battery charging [3]-[6], [11]. The performance of these systems requires an exchange of information between the transmitter and the receiver, i.e. the operation frequency, the required power, the vehicle identification and the payment information. However, a high intensity EMF generated by WPT system may introduce highly undesired influence on the communication channel which could be a severe problem [12]-[13].

Furthermore, the strong electromagnetic field produced by WPT system may not only adversely influence other electrical and electronic equipments, but also it can present danger for the human health. Thus, the electromagnetic compatibility study of the wireless energy transfer system has become an urgent priority [14]. It is important to estimate the possible strong EMF impact of the WPT electromagnetic emissions on the: environment, human health and data channel for a practical use of wireless power transfer. To guarantee the safety of the public and the workers, measurement and evaluation of human exposure to EMFs are essential.

To protect the environment, the human health and the data transmission channel, it is essential to take steps to mitigate the EMF levels produced by the WPT systems.

As far as it is known, the general and wide overview comprising the various issues of WPT on EMC has not been reported yet [15]. This paper is a contribution in the field of EMC problems in the wireless energy transfer systems. This paper is structured as follows.

Section II presents the radiation safety standards. Section III provides electromagnetic field impact on the human health and on the communications system. Section IV provides the modelling of the WPT system. Section V presents the case study. Section VI provides analysis of the results. Finally, the Section VII outlines the conclusion.

\section{Radiation Safety Standards}

There are various international organizations which have been involved in the preparation and formulation of the radio frequencies (RF) safety standards for the human being. The international standards, as a rule, have no regulatory or binding status and become mandatory only if officially adopted within a country. The exposure guidelines are based on a critical analysis of scientific research. The limits are established according to scientific studies and are reviewed periodically, to ensure that they meet the current scientific requirements [16][18].

The most respected organization in the safety standards development at the international level is the International Commission on Non-Ionizing Radiation Protection (ICNIRP). The ICNIRP is an independent organization formally recognized by World Health Organization (WHO), which develops guidelines for exposure limits and provides the material for the WHO publications on non-ionizing radiation. Another internationally well recognized organization which has been involved in the development of safety standards is the Institute of Electrical and Electronics Engineers (IEEE) in USA. The safety standards developed by these organizations are generally similar, with a few exceptions [18]. Among the regional organizations dealing with the preparation and formulation of the RF safety standards for the human being, is to be mentioned the European Committee for Electrotechnical Standardization (CENELEC) and the European Committee for Standardization (CEN).

The guidelines for exposure to $\mathrm{RF} /$ microwaves published by ICNIRP were adopted in most Western European countries and in some industrialized countries outside Europe, i.e., Australia. Some Eastern European countries like Russia, Poland, and Bulgaria have adopted more strict limits of the order of $2 \%$ of ICNIRP [16].

Most of the countries follow different standards for the occupational public (workers) and for the general public exposure [17]-[18]. The workers are considered to be healthy adults, aware of the risks and being exposed only during their working hours.

On the other hand, the general public represents a diversity of the health sensitivity and it is potentially exposed $24 \mathrm{~h}$ daily, being unconscious of the risks. So, for general public the exposure limits are stricter. For example, according to the ICNIRP Guideline for the frequency range of $3 \mathrm{kHz}$ to $1 \mathrm{MHz}$, the exposure limits for the general public are one seventh of those applied to occupational public.

The ICNIRP reference levels for occupational and general public exposure [17] are shown in Fig. 1.

\section{Electromagnetic Field Impact}

\section{III.1. Health Effects Associated with Radiofrequency Exposure}

The intensive use of the electric energy has led to the fact that in the modern information society a new and significant pollution factor was formed in the last third of the XX century - the electromagnetic one. 


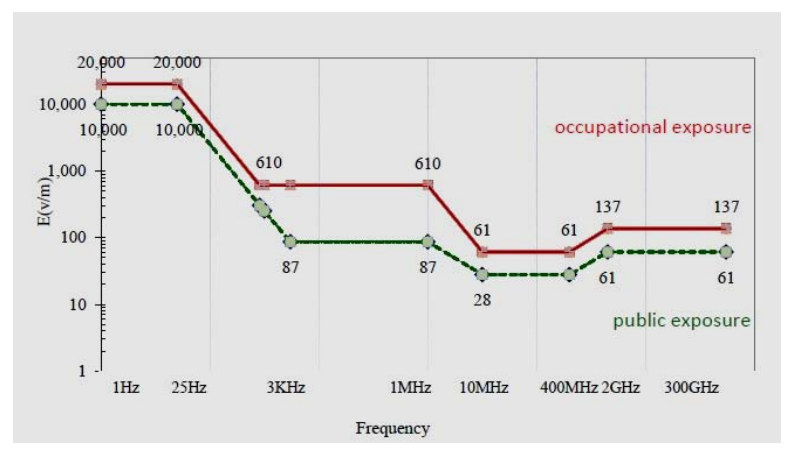

Fig. 1. Reference levels for occupational and public exposure [19]

The development of modern technologies of information and energy transmission, remote control and monitoring, as well as some of the types of transport, has contributed to the appearance of electromagnetic interference (EMI). The current technologies have become a source of EMI as a result of the generated EMF, thus leading to electromagnetic radiation [20].

The electromagnetic energy transferred by WPT system and radiated into the surrounding environment will be absorbed by humans and other living organisms.

Contrary to the wireless communications, the level of the transmitted electromagnetic power required for largescale or commercial implementation of wireless energy transfer could be substantial [21].

Several developers claim that the technology is safe for humans, but it is impossible to predict the impact on human being of such exposure over time. The damage caused by EMFs is still an open question since there is no clear evidence of its negative influence on human health. In the recent years, the number of scientific researches dedicated to the impact of EMF on the living organisms has significantly increased [20]. The human body is a good conductor of electricity due to the fact that it consists of conductive tissues, i.e., neural tissues and fluids as blood, lymph, intercellular fluid. On other hand, the human body as a whole, as well as its individual parts represents resonators and hence antennas. The human body is capable to resonate with the electromagnetic radiation in resonance with the wavelength of the transmitted energy and the resonance may occur related to the whole wavelength or a fraction of it. Thus, the human body of $1.8 \mathrm{~m}$ acts as antenna for the frequencies $167 \mathrm{MHz}, 42 \mathrm{MHz}$ and $10 \mathrm{MHz}$ [22]. The same applies to the body parts. The resonant frequencies of the human body are shown in Fig. 2. According to [20] the electromagnetic spectrum can be divided into frequency bands in terms of environmental effects, namely:

- radio frequency $(100 \mathrm{kHz}<f \leq 300 \mathrm{GHz})$;

- intermediate frequency (IF) $(300 \mathrm{~Hz}<f \leq 100 \mathrm{kHz})$ :

- extremely low frequency (ELF) $(0<f \leq 300 \mathrm{~Hz})$;

- $\quad$ static $(0 \mathrm{~Hz})$.

Many scientific studies have investigated the possible health effects of the electromagnetic radiations [22]-[25].

Electric currents exist naturally in the human body and play an important role in the normal physiological functions [17].

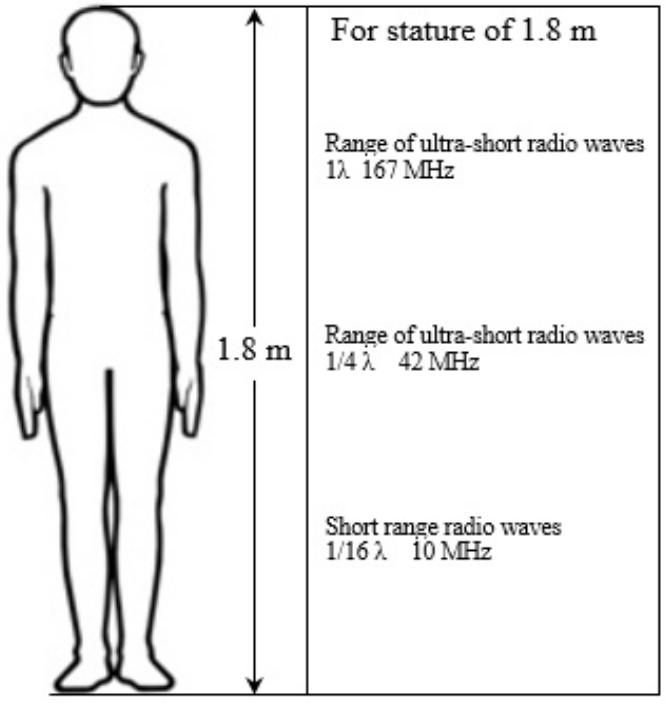

Fig. 2. Resonant frequencies of the human body [21]

Nervous system is responsible for transmitting electric impulses throughout the body.

The results of exposure of the body to the EMF depend on the EMF frequency and strength. Numerous studies have concluded that EMF is harmful and can have adverse effect on the human body. When the lowfrequency electromagnetic field passes through the body it can carry its clock frequency to biological structures (nerves, muscle fibers), and thereby disorders their function. The consequence of this can be heart rhythm disturbances, as well as other manifestations [22].

Electromagnetic radiation incident on the body partially penetrates inside to a short depth into the tissue decreasing exponentially [24]. It should be noted, that at low frequencies the penetration depth is more significant.

The EMF energy absorbed by the body tissue is converted into heat which could be dangerous in case of long period of exposure [25]. This heating effect depends on the power and on the frequency of the radiation.

To assess human exposure to electromagnetic fields a measure of the heat absorbed by the unit mass of tissue, the specific absorption rate (SAR), is used. The SAR measuring unit is $\mathrm{W} / \mathrm{kg}$. Furthermore, the EMF exposure has a cumulative effect, growing with the time of exposure and the dose [23]. Even weak electric and magnetic fields, in case of prolonged exposure, can produce potential health effects. It means that in the event of chronic exposure health problems, such as degenerative processes in the central nervous system, leukemia, brain cancer, hormonal disorders can appear [22]. Thus, more research about the cumulative effect of electromagnetic fields on the human health is needed.

The WPT equipment may induce strong electromagnetic field in the vicinity of the system, and as a result high voltages and currents may be induced in the human body tissue [26]. Consequently, it is necessary to evaluate the human exposure to the electromagnetic fields produced by WPT system [27]. Thus, the measurement of electromagnetic field strength in the 
vicinity of the WPT system and comparing the results with the reference level of the ICNIRP guidelines can be valuable for the human body exposure to be evaluated.

\section{III.2. EMF Impact on the Communications System}

The main purpose of the WPT system is to transmit energy. However, it is inevitable to transmit simultaneously the energy together with the information signals. This approach can be widely used for several types of applications, i.e., portable electronic equipment, high power equipment and EVs. The wireless charging systems play an important role in the charging of the EV.

In this kind of application, the charging depends significantly on communications [12].

The communication channel allows for sending data from the charger to the EV and sending the feedback signals. The data transfer allows for recognizing the receivers of energy and thus to optimize the energy flow [4]. The communication system can be based on the modulation of the energy flow, or on separated frequency bands for the energy and for the data [4].

For example, the wireless power and data transmission system with resonant coils tuned at the same working frequency is analyzed in [28]-[30]. The information, in this case, is transferred by modulation of the energy flow.

However, there is a problem of the influence between the energy transfer and the data transmission. In order to avoid this problem, the modulation methods must be more sophisticated: amplitude shift keying (ASK), frequency shift keying (FSK) and phase shift keying (PSK). Another approach applies separated coils for the energy transfer and the data transmission [31].

A special data coils geometry is proposed in [32] to reduce the mutual coupling between the two channels (power and data). Nevertheless, these approaches also present some disadvantages. One of the main disadvantages of the described systems is the limited data transmission rate. Other disadvantage is the complicated design of the coils, since it is very difficult to obtain sufficient isolation between the coils of the energy transfer and data transmission. In order to attenuate these problems, it is proposed to use very high frequencies for the data transmission (in the order of $\mathrm{GHz}$ ) [33]. It was also proposed to transmit the data by various wireless communications protocols, i.e., Bluetooth and Near Field Communication [4]. The application of very high frequencies for the data transmission allows for a higher data transmission rate. In [34]-[35], it was proposed the Bluetooth technology for the data transmission, especially for the automotive industry.

The communication channel operates at very low power (less than $100 \mathrm{~mW}$ ). In the same time, the WPT system transfers energy at $\mathrm{kW}$ power level and the risk of electromagnetic interference to the communication channel is high. Thus, it is necessary to guarantee that the electromagnetic field generated by the WPT system will not disturb the communication between the transmitter and the receiver.

\section{Modelling}

The schematic representation of a WPT system is shown in Fig. 3. The equivalent circuit of the WPT system [36] is shown in Fig. 4.

The two coils are connected together via magnetic field, characterized by coupling coefficient that is given by:

$$
k_{12}=\frac{L_{M}}{\sqrt{L_{1}} L_{2}}
$$

The circuit equations for the primary and secondary are given from (2) to (4) using Kirchhoff's current/voltage laws:

$$
\begin{gathered}
\left(R_{1}+j \omega L_{1}+\frac{1}{j \omega C_{1}}\right) I_{1}-j \omega L_{M} I_{2}=V_{S} \\
\left(R_{L}+R_{2}+j \omega L_{2}+\frac{1}{j \omega C_{2}}\right) I_{2}-j \omega L_{M} I_{1}=0 \\
I_{M}=I_{1}-I_{2}
\end{gathered}
$$

The loop impedances for the two coils are given by:

$$
\begin{gathered}
Z_{1}=R_{1}+j \omega L_{1}+\frac{1}{j \omega C_{1}} \\
Z_{2}=R_{L}+R_{2}+j \omega L_{2}+\frac{1}{j \omega C_{2}}
\end{gathered}
$$

The currents of the primary and secondary are given by:

$$
\begin{aligned}
& I_{1}=\frac{Z_{2} V_{S}}{Z_{1} Z_{2}+\omega^{2} L_{M}^{2}} \\
& I_{2}=\frac{j \omega L_{M} V_{S}}{Z_{1} Z_{2}+\omega^{2} L_{M}^{2}}
\end{aligned}
$$

Under condition of resonance the reactive part of the impedance of the coils becomes zero.

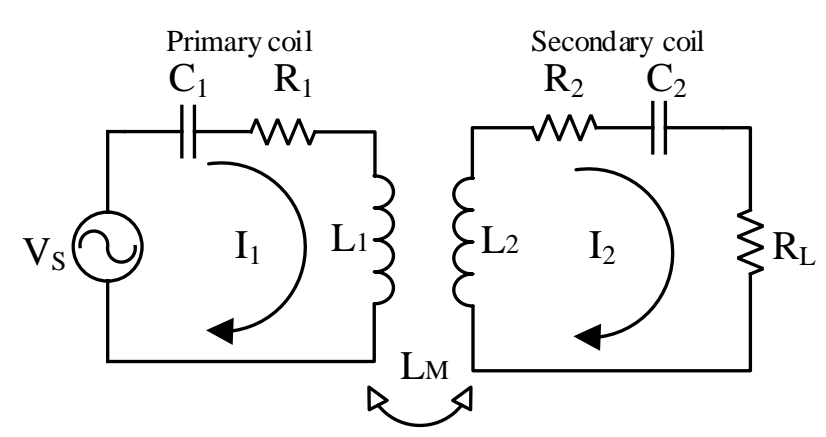

Fig. 3. Schematic representation of a WPT system 


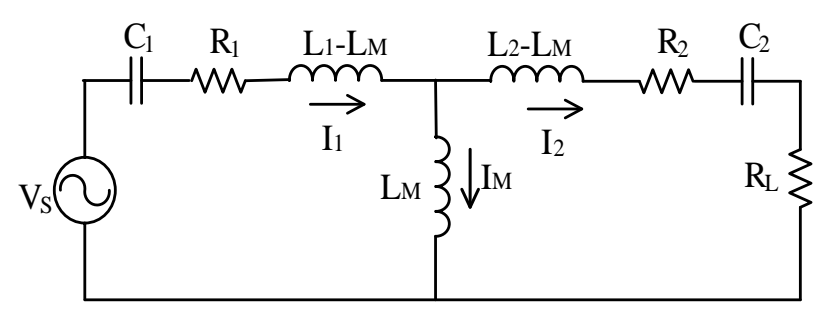

Fig. 4. Equivalent circuit of the WPT system

Therefore, at the resonant frequency the currents $I_{1}$ and $I_{2}$ can be simplified and given by:

$$
\begin{aligned}
& I_{1}=\frac{R_{2}^{\prime} V_{S}}{R_{1}^{\prime} R_{2}^{\prime}+\omega^{2} L_{M}{ }^{2}} \\
& I_{2}=\frac{j \omega L_{M} V_{S}}{R_{1}^{\prime} R_{2}^{\prime}+\omega^{2} L_{M}{ }^{2}}
\end{aligned}
$$

where $R_{1}^{\prime}$ and $R_{2}^{\prime}$ respectively are the total transmitting and receiving circuit resistances, are given by:

$$
\begin{gathered}
R_{1}^{\prime}=R \\
R_{2}^{\prime}=R_{2}+R_{L}
\end{gathered}
$$

The power of the input side $P_{\text {in }}$ and output power delivered to the load $P_{\text {out }}$ is given by:

$$
\begin{gathered}
P_{\text {in }}=V_{S} I_{1} \cos \varphi \\
P_{\text {out }}=R_{L} I_{2}{ }^{2}=\frac{R_{L} \omega^{2} L_{M}{ }^{2} V_{S}{ }^{2}}{\left(R_{1}{ }^{\prime} R_{2}{ }^{\prime}+\omega^{2} L_{M}{ }^{2}\right)^{2}}
\end{gathered}
$$

In accordance with the previous equations, the power transfer efficiency can be given by:

$$
\eta=\frac{P_{\text {out }}}{P_{\text {in }}}=\frac{R_{L} \omega^{2} L_{M}{ }^{2}}{R_{2}{ }^{\prime}\left(R_{1}{ }^{\prime} R_{2}{ }^{\prime}+\omega^{2} L_{M}{ }^{2}\right) \cos \varphi}
$$

In (15) the power transfer efficiency depends on the operation frequency and circuit parameters; the efficiency decreases rapidly with increasing distance from its resonant operation; the high quality factor of transmitter and receiver coils is of crucial importance for the WPT system efficiency at resonance frequency.

\section{Case Study}

The analysis was focused on the measurement of the electromagnetic radiation caused by WPT system for charging of electric vehicles.
The test equipment used to perform measurements was composed by an experimental setup of WPT system and the measurement system. The WPT system is mounted at the Power Electronics Supply Laboratory of the Technical University of Sofia.

Fig. 5 shows the wireless charging stand for electric vehicles Li-Ion batteries [37] operating from $30 \mathrm{kHz}$ to $200 \mathrm{kHz}$ frequency. Table I shows the characteristics of the WPT system used in this study. The main blocks of studied WPT system are shown in Fig. 6.

The measurement equipment is shown in Fig. 7 and consists of a basic unit, i.e. a measuring instrument Narda SRM-3000 Selective Radiation Meter, and an antenna for the $100 \mathrm{kHz} \div 3 \mathrm{GHz}$ frequency domain.

The measurement of the electromagnetic fields was performed with the experimental unit of electronic load with programmed resistance $R_{L}=30 \Omega$.

The aim of the measurement was to determine the level of external electromagnetic radiation at different frequencies. The measurement equipment is calibrated according to ISO 9000 standard and uses Windows compatible software for EMI measurement.

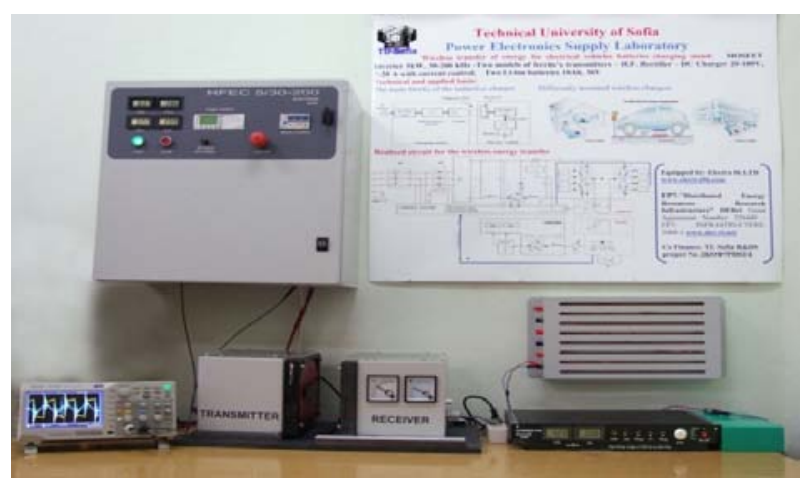

Fig. 5. WPT system: experimental setup

TABLE I

CHARACTERISTICS OF THE EXPERIMENTAL SETUP

\begin{tabular}{cc}
\hline \hline Item & Specification \\
\hline AC Rectifier and HF & Pmax $=5 \mathrm{~kW}$, frequency $30 \mathrm{kHz}-200 \mathrm{kHz}$ \\
Ferrite core system of & at a distance $\Delta$ from $40 \mathrm{~mm}$ to $150 \mathrm{~mm}$ \\
Transmitter and Receiver & \\
HF Rectifier & AC RMS $400 \mathrm{~V} / 15 \mathrm{~A}, \mathrm{DC} 500 \mathrm{~V}, 10 \mathrm{~A}$ \\
DC charger & $20 \mathrm{~V}-180 \mathrm{~V}, 2 \mathrm{~A}-20 \mathrm{~A}$ with current control \\
Load resistors $\left(R_{L}\right)$ & between $5 \Omega$ and $150 \Omega$ \\
Two Li-Ion batteries & $10 \mathrm{Ah}, 36 \mathrm{~V}$ \\
\hline \hline
\end{tabular}

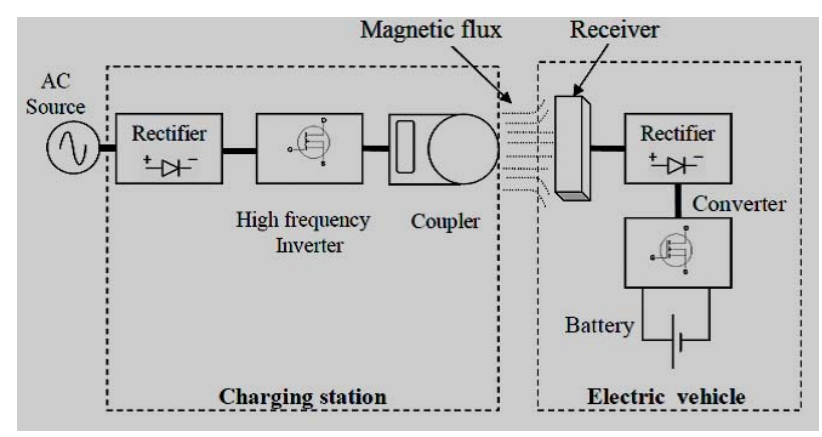

Fig. 6. Main blocks of the inductive charger 


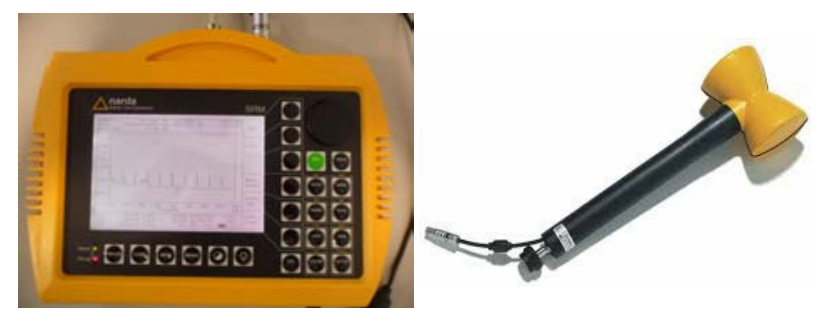

Fig. 7. Measurement equipment with antenna

Any vehicle is essentially Faraday cage, protecting the driver and passengers from external radio frequency interference. Nevertheless, there is a possibility that humans or animals could be found near to the EV during the charging. In this case there is a risk to be exposed to a strong electromagnetic radiation.

So, taking into account this possibility, the measurements were performed at the transmitting distance of $4 \mathrm{~cm}, 20 \mathrm{~cm}, 40 \mathrm{~cm}$ and $100 \mathrm{~cm}$.

The harmonics generated by WPT system operating at $142 \mathrm{kHz}$ frequency at transferred power $P_{\text {out }}=800 \mathrm{~W}$ and at the distance of measurement of $4 \mathrm{~cm}$ is shown in Fig. 8. In the Fig. 9, which shows in detail the harmonics generated by the WPT system, a pulse component of the signal can be observed. The electromagnetic field waveform is not a perfect sinusoid: small peaks exist which testifies of rich harmonics content. From the point of view of the energy the harmonic content is not important, but it could influence the data transfer.

The amplitudes of main harmonics generated by WPT system operating at $142 \mathrm{kHz}$ frequency at different distances of measurement and $P_{\text {out }}=800 \mathrm{~W}$ is shown in Fig. 10. The full range of electromagnetic interference harmonic components generated by the WPT system operating at $142 \mathrm{kHz}$ frequency at different distances of measurement and $P_{\text {out }}=800 \mathrm{~W}$ is shown in Fig. 11 .

The distance from the WPT system to the measurement antenna plays a key role. As it is shown in Fig. 12 the harmonics are going to disappear at the distance of measurement of $100 \mathrm{~cm}$. When the power is very low, the harmonics are very low too.

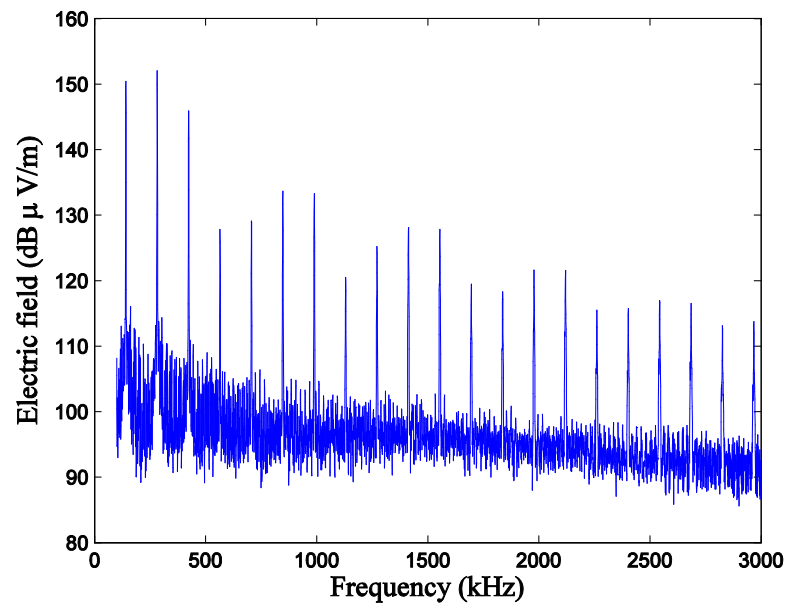

Fig. 8. WPT system: harmonics generated at $142 \mathrm{kHz}$ frequency, $P=800 \mathrm{~W}$, distance of measurement $4 \mathrm{~cm}$

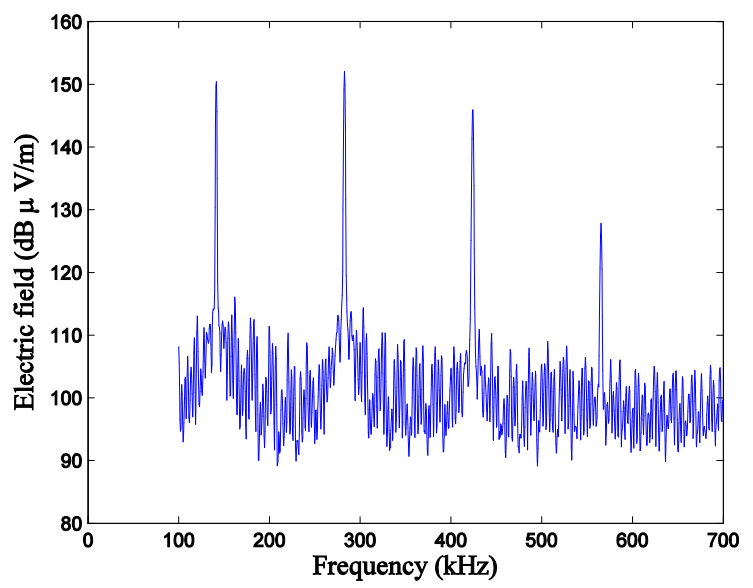

Fig. 9. WPT system: harmonics generated at $142 \mathrm{kHz}$ frequency, $P=800 \mathrm{~W}$, distance of measurement $4 \mathrm{~cm}$ (detail)

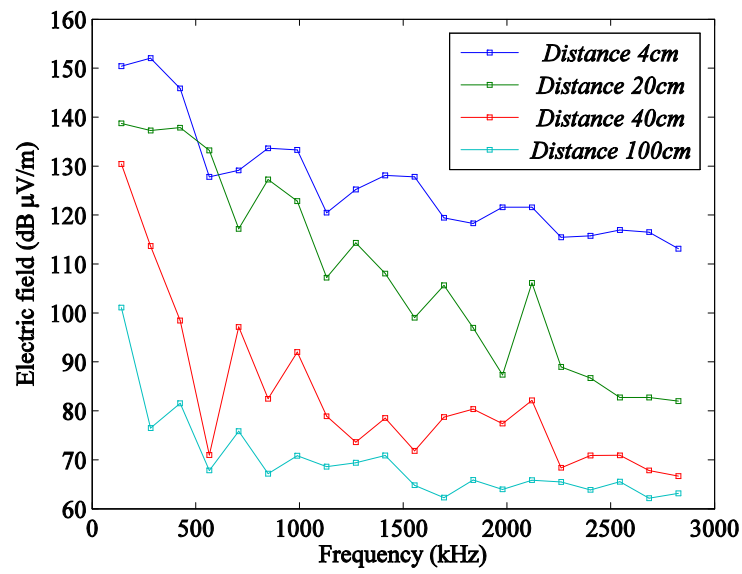

Fig. 10. Electric Field generated by WPT system at $142 \mathrm{kHz}$ frequency, $P=800 \mathrm{~W}$, at different distances (main harmonics)

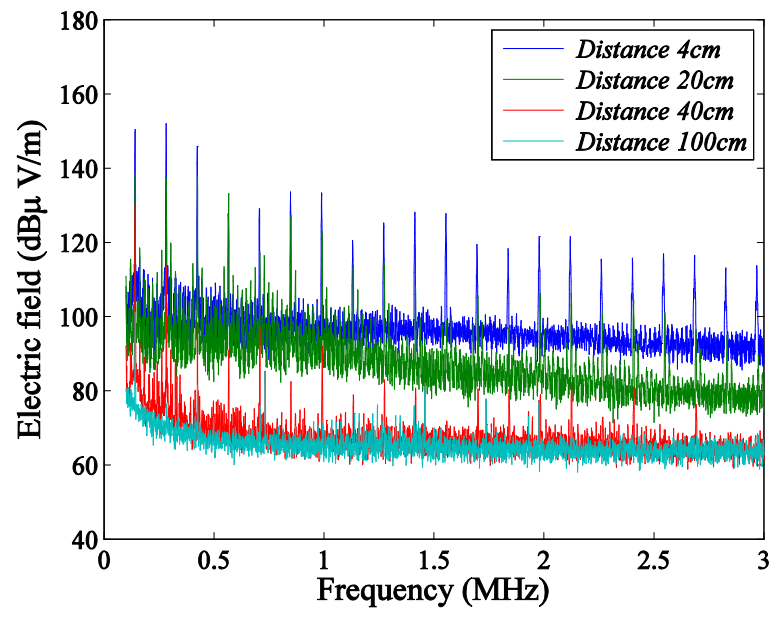

Fig. 11. Electromagnetic interferences generated by WPT system at $142 \mathrm{kHz}$ frequency at different distance of measurement

The harmonics grow significantly if the transmitted power is growing and the distance of measurement is decreasing. The practical values of the electric field $\mathrm{E}$ (the 1 st harmonic) in function of the distance of measurement for different values of transferred power [38] is shown in Fig. 12. 


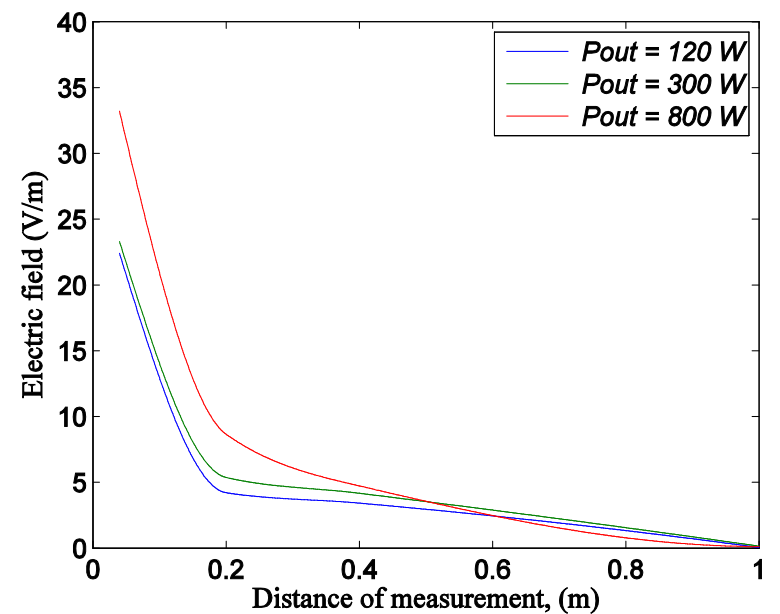

Fig. 12. Electromagnetic interferences generated by WPT system at $142 \mathrm{kHz}$ frequency at different distance of measurement

As expected, the electric field is much stronger directly adjacent to the WPT equipment, but decreases quickly with the distance. Finally, the growing power and the shorter distances to the influenced electronic equipment or human being, presents a higher danger.

\section{Discussing of Results}

As a defense against the potential health effects, the international electromagnetic protection organizations imposed limits to the occupational and general public exposure to the radio frequencies.

The most respected standardization organization in the area of EMF protection, ICNIRP, published in 1998 safety guidelines for limiting exposure to provide protection against known adverse health effects [17].

These guidelines are applied to time-varying electric, magnetic and electromagnetic fields (up to $300 \mathrm{GHz}$ ).

In 2010 the guidelines were revised and updated, namely some new guidelines for varying fields from 1 $\mathrm{Hz}$ to $100 \mathrm{kHz}$ were published.

For the evaluation of the exposure to the EMI produced by the studied WPT system, it is necessary to compare measured field and the reference level of the ICNIRP. The obtained experimental values of electric field strength (1st harmonic) at different distances of measurement are shown in Table II. These results also confirm that electric field is becoming weaker with the distance increasing.

In the Fig. 1, which shows the ICNIRP Guidelines for public and occupational exposure, it can be observed that for frequency range of $3 \mathrm{kHz}-1 \mathrm{MHz}$ the level reference for general public exposure is $E=87 \mathrm{~V} / \mathrm{m}$.

TABLE II

ELECTRIC FIELD STRENGTH

\begin{tabular}{ccc}
\hline \hline \multirow{2}{*}{ Distance of measurement $(\mathrm{cm})$} & \multicolumn{2}{c}{ Electric Field (1st harmonic) } \\
\cline { 2 - 3 } & $\mathrm{E}(\mathrm{V} / \mathrm{m})$ & $\mathrm{E}(\mathrm{dB} \mu \mathrm{V} / \mathrm{m})$ \\
\hline 4 & 33.19 & 150.42 \\
20 & 8.65 & 138.74 \\
40 & 3.32 & 130.42 \\
100 & 0.11 & 101.12 \\
\hline \hline
\end{tabular}

Analyzing the results obtained with the studied WPT system it is possible to verify that the maximum value of the electromagnetic emission is $33.19 \mathrm{~V} / \mathrm{m}$. To emphasize that, this maximum value was obtained at a very short distance $(4 \mathrm{~cm})$ and that value decreases very fast with the distance increasing. Thus, from the comparison with the referred guidelines it is possible to conclude that practical values of EMI produced by considered WPT system is significantly less than the ICNIRP reference for time-varying electric fields (of 3 $\mathrm{kHz}-150 \mathrm{kHz}$ frequency range wherein the WPT equipment operates).

It was shown, that the WPT system produced electric fields with higher frequencies and multiples of the fundamental. However, the amplitude of these high frequency electric fields presents a marked reduction.

\section{Conclusion}

This paper presented a study related to the measuring of radio frequency emissions produced by the WPT system. The purpose is to determine the level of electromagnetic interferences generated by wireless power transfer equipment in a $\mathrm{kHz}$ frequency range.

In fact, the electromagnetic interferences measurement and the evaluation of human exposure to electromagnetic fields as well are essential to guarantee occupational and general public safety. In this study the measurement of electromagnetic field strength close to the WPT system and the comparison of measured field and the reference level of the ICNIRP were performed.

The value of the electromagnetic emission produced by the studied WPT system is $33.19 \mathrm{~V} / \mathrm{m}$, what is significantly less than the reference level of $E=87 \mathrm{~V} / \mathrm{m}$ defined by ICNIRP for general public exposure.

This study allows to evaluate the possible impact of the electromagnetic emissions upon the environment and human health during a practical use of EV batteries wireless charging. From the obtained experimental results, it was verified that the emissions in the $\mathrm{MHz}$ range produced by WPT equipment operating at $\mathrm{kHz}$ frequency range are irrelevant at a longer distance from the transmitter. At a closer distance from the WPT system the electromagnetic interference is much higher.

The obtained results were also compared to the reference level of the ICNIRP guideline. From this comparison it was possible to verify that all of the results obtained from the several tests presented values that were below the required by that guideline.

\section{Acknowledgements}

The authors express their gratitude for the friendly help obtained from the colleagues of INESC INOVE, Lisbon, and their help made possible the measurements. The presentation of the work is partly funded by CTS/UNINOVA, Faculty of Science and Technology (FCT), University Nova de Lisboa. The laboratory and the Faraday Cage are also made available by the FCT 
faculty. Gratitude is expressed to some other institutions, presented by their members: IDMEC, Instituto Superior Técnico, Universidade de Lisboa and the EST of the Polytechnic Institute of Setubal.

\section{References}

[1] J.T. Boys, G.A. Covic, A.W. Green, Stability and control of inductively coupled power transfer systems, IEE Proceed. Electric Power Applications, vol. 147, n. 1, 2002, pp. 37-43.

[2] C. Zhu, K. Liu, C. Yu, R. Ma, H. Cheng, Simulation and experimental analysis on wireless energy transfer based on magnetic resonances, The IEEE Vehicle Power and Propulsion Conference, 2008, pp. 1-4, Harbin, China.

[3] A. Kurs, A. Karalis, R. Moffatt, J.D. Joannopoulos, P. Fisher, M. Solja, Wireless power transfer via strongly coupled magnetic resonances, Science, vol. 317, n. 5834, 2007, pp. 83-86.

[4] S. Li, C.C. Mi, Wireless power transfer for electric vehicle applications, IEEE Journal of Emerging and Selected Topics in Power Electronics, vol. 3, n. 1, 2015, pp. 4-17.

[5] T. Imura, H. Okabe, Y. Hori, Basic experimental study on helical antennas of wireless power transfer for electric vehicles by using magnetic resonant couplings, The IEEE Vehicle Power and Propulsion Conference, 2009, pp. 936-940, Dearborn, USA.

[6] R. Medeiros, S.S. Valtchev, S. Valtchev, The efficient and stable charging of electric vehicle batteries: simplified instantaneous regulation, Technological Innovation for Value Creation, Heidelberg: Springer, 2012, pp. 363-374.

[7] E.N. Baikova, S.S. Valtchev, R. Melício, V.M. Pires, Electromagnetic interference from a wireless power transfer system: experimental results, The International Conference on Renewable Energies and Power Quality, 2016, pp. 1-5, Madrid, Spain

[8] W.C. Brown, The history of power transmission by radio waves, IEEE Transaction on Microwave Theory and Techniques, vol. 32, n. 9, 1984, pp. 1230-1242.

[9] S. Ahn, J. Pak, T. Song, H. Lee, J.-G. Byun, D. Kang, C.-S. Choi, E. Kim, J Ryu, M.Kim, Y.Cha, Y. Chun, C.-T. Rim, J.-H. Yim, D.-H. Cho, J. Kim, Low frequency electromagnetic field reduction techniques for the on-line electric vehicle (OLEV), The IEEE International Symposium on Electromagnetic Compatibility, 2010, pp. 625-630, Fort Lauderdale, USA.

[10] M. Kline, I. Izyumin, B. Boser, S. Sanders, Capacitive power transfer for contactless charging, The IEEE 26th Annual Applied Power Electronics Conference and Exposition, 2011, pp. 1398-1404, Fort Worth, USA.

[11] A.P. Sample, D.A. Meyer, J.R. Smith, Analysis, experimental results, and range adaptation of magnetically coupled resonators for wireless power transfer, IEEE Transactions on Industrial Electronics, vol. 58, n. 2, 2009, pp. 544-554.

[12] E.N. Baikova, S.S. Valtchev, R. Melício, V.M. Pires, Electromagnetic interference impact of wireless power transfer system on data wireless channel, Technological Innovation for Cyber-Physical Systems, Springer, 2016, pp. 293-301.

[13] E.N. Baikova, S.S. Valtchev, R. Melício, V. Fernão Pires, Wireless power transfer impact on data channel, The Int. Symposium on Power Electronics, Electrical Drives, Automation and Motion, 2016, pp. 582-587, Capri, Italy.

[14] M. Kim, S. Kim, S. Ahn, Y. Chun, S. Park, Low frequency electromagnetic compatibility of wirelessly powered electric vehicles, The International Symposium on Electromagnetic Compatibility, 2014, pp. 426-429, Tokyo, Japan.

[15] S. Obayashi, H. Tsukahara, EMC issues on wireless power transfer, The International Symposium on Electromagnetic Compatibility, 2014, pp. 601-604, Tokyo, Japan.

[16] T. Kosatsky, A. Zitouni, M. Shum, H.D. Ward, R.P. Gallagher, F. Anselmo, R. Ross, L. Freeman, J. Oda, S. Lidstone, L. Miu, M. Wiens, M. Phillips, T. Spock, Radiofrequency toolkit for environmental health practitioners, Technical report, Vancouver, BC: BC Centre for Disease Control and National Collaborating Centre for Environmental Health, 2013. (Available: https://www.emf-portal.org/en/article/26950).
[17] International Commission on Non-Ionizing Radiation Protection (ICNIRP), Guidelines for limiting exposure to time-varying electric, magnetic and electromagnetic fields (up to $300 \mathrm{GHz}$ ), Health Physics, vol. 74, 1998, pp. 494-522.

[18] "IEEE Standard for Safety Levels with Respect to Human Exposure to Radio Frequency Electromagnetic Fields, $3 \mathrm{kHz}$ to $300 \mathrm{GHz}$ ", IEEE Std. C95.1-2005.

[19] H. Mazar, Technical limits of human exposure to RF from cellular base stations and handsets, The Professional Meeting, 2013, Jerusalem, Israel. (Available: http://www.sviva.gov.il/subjectsEnv/Radiation/Radiation/nonionising/Documents/RFCellularexposure.pdf).

[20] G. Redlarski, B. Lewczuk, A. Żak, A. Koncicki, M. Krawczuk, J. Piechocki, K. Jakubiuk, P. Tojza, J. Jaworski, D. Ambroziak, L. Skarbek, D. Gradolewski, The Influence of Electromagnetic Pollution on Living Organisms: Historical Trends and Forecasting Changes, BioMed Research International, vol. 2015, pp. 1-18.

[21] J.C. Lin, Wireless power transfer for mobile applications, and health effects, IEEE Antennas and Propagation Magazine, vol. 55, n. 2, 2013, pp. 250-253.

[22] A. Stozharov, Medical Ecology: Textbook, (Vysshaja Shkola Publishing house, 2007, 270-302). (Available (in Russian): http://www.grsmu.by/files/file/university/cafedry/patologicheskoi -anatomii/files/ekolog_medichina.pdf).

[23] Scientific Committee on Emerging and Newly Identified Health Risks, Opinion on Potential health effects of exposure to electromagnetic fields (EMF), Luxembourg: European Commission, 2015, pp. 15-48.

[24] A.B. Rifai, M.A. Hakami, Health hazards of electromagnetic radiation, Journal of Biosciences and Medicines, vol. 2, n. 8, 2014, pp. 1-12.

[25] A. Mahajan, M. Singh, Human health and electromagnetic radiations, International Journal of Engineering and Innovative Technology, vol. 1, n. 6, 2012, pp. 95-97.

[26] A Christ, M. G. Douglas, J. M. Roman, E. B. Cooper, A. P. Sample, B. H. Waters, J. R. Smith, N. Kuster, Evaluation of wireless resonant power transfer systems with human electromagnetic exposure limits, IEEE Transactions on Electromagnetic Compatibility, vol. 55, n. 2, 2013, pp. 265-274.

[27] T. Iwamoto, T. Arima, T. Uno, K. Wake, K. Fujii, S. Watanabe, Measurement of electromagnetic field in the vicinity of wireless power transfer system for evaluation of human-body exposure, The International Symposium on Electromagnetic Compatibility, 2014, pp. 529-532, Tokyo, Japan.

[28] C.-T. M. Wu, J.S. Sun, T. Itoh, A simple self-powered AMdemodulator for wireless power/data transmission, The 42th European Microwave Conference, 2012, pp. 325-328, Amsterdam, Holland.

[29] G.V. Tibajia, M.C. Talampas, Development and evaluation of simultaneous wireless transmission of power and data for oceanographic devices, IEEE Sensors, 2011, pp. 254-257, Limerick, Ireland.

[30] G.B. Hmida, H. Ghariani, M. Samet, Design of a wireless power and data transmission circuits for implantable biomicrosystem, Biotechnology, vol. 6, n. 2, 2007, pp. 153-164.

[31] T. Bieler, M. Perrottet, V. Nguyen, Y. Perriard, Contactless power and information transmission, IEEE Transactions on Industry Applications, vol. 38, n. 5, 2001, pp. 1266-1272.

[32] C. Rathge, D. Kuschner, High efficient inductive energy and data transmission system with special coil geometry, The 13th European Conference on Power Electronics and Applications, 2009, pp. 1-8, Barcelona, Spain.

[33] V.N. Yashchenko, D.S. Kozlov, I.B. Vendik, Dual-mode resonator for the dual-band system of wireless energy transfer with simultaneous data transmission, Progress In Electromagnetics Research Letters, vol. 50, 2014, pp. 61-66.

[34] R.J. Green, Z. Rihawi, Z.A. Mutalip, M.S. Leeson, M.D. Higgins, Networks in automotive systems: the potential for optical wireless integration, 14th International Conference on Transparent Optical Networks, 2012, pp. 1-4, Coventry, England.

[35] A. Ramteke, A. Gurmule, K. Sonkusare, Wireless automotive communications, Discovery, vol. 18, n. 53, 2014, pp. 89-92.

[36] T. Imura, Study on maximum air-gap and efficiency of magnetic resonant coupling for wireless power transfer using equivalent 
circuit, The IEEE International Symposium on Industrial Electronics, 2010, pp. 3664-3669, Bari, Italy.

[37] S. Valtchev, R. Neves-Medeiros, A. Krusteva, G. Gigov, P. Avramov, A wireless energy transceiver based on induction heating equipment, The 16th International Power Electronics and Motion Control Conference, 2014, pp. 2019-2025, Antalya, Turkey.

[38] E.N. Baikova, S.S. Valtchev, R. Melício, A. Krusteva, G. Gigov, Study on electromagnetic emissions from wireless energy transfer, The IEEE 17th International Conference on Power Electronics and Motion Control, 2016, pp. 485-490, Varna, Bulgaria.

\section{Authors' information}

\section{${ }^{1}$ UNINOVA-CTS.}

${ }^{2}$ Faculdade de Ciências e Tecnologia, Universidade Nova de Lisboa.

${ }^{3}$ EST, Instituto Politécnico de Setúbal.

${ }^{4}$ IDMEC, Instituto Superior Técnico, Universidade de Lisboa.

${ }^{5}$ Departamento de Física, Escola de Ciências e Tecnologia, Universidade de Évora.

${ }^{6}$ Technical University of Sofia.

\section{${ }^{7}$ INESC-ID Lisboa.}

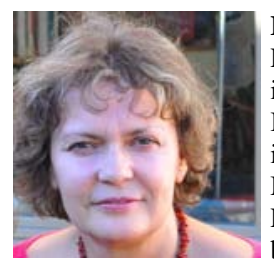

Elena N. Baikova, has a MSc Degree in Electrical Power Systems and Grids completed in 1981 in the Moscow Power Engineering Institute. Since 1980 until 1992 is an Professor in the Technical School of Light Industry in Moscow Granted the equivalence degree in Electrical Engineering and Computer 19/03/99 by order of the Scientific Council of the Instituto Superior Técnico, Technical University of Lisbon. Recognition of the Master's degree in Electrical and Computer Engineering from Universidade Nova de Lisboa in 2009. Since 2009 is a PhD student in Electrical and Computer Engineering at the Faculty of Science and Technology, Universidade Nova de Lisboa.. Since 2000 is an assistant Professor in the Superior School of Technology of Setubal Polytechnic Institute.

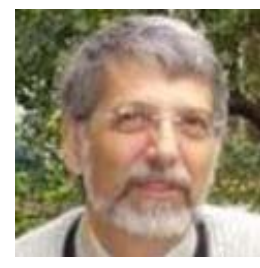

Stanimir S. Valtchev (IEEE: M'93, SM'08) Professor Auxiliar of Power Electronics, Department of Electrical Engineering of the Faculty of Science and Technology, Universidade Nova de Lisboa, Portugal. Best graduate (MSc) of 1974, Technical University Sofia (TUS), in semiconductor and electronics technology, military service in radars, researcher in medical equipment and power converters and laser supplies, Auxiliary Director of the Centre of Robotics of TUS. In 1987 worked in TU Delft as Assistant Professor, since 1988 Assistant Professor in TUS (Power Supplies and Converters), Deputy Dean of TUS. Working on HF resonant power converters, IEEE Meritorious Paper Award, 1997, Best Paper Award from PEMC2014. Since 1994, teaching and consulting in Portugal and in the Netherlands. Based on a versatile experience, the research includes energy conversion, energy harvesting, wireless energy transfer, electric vehicles, energy management and storage, smart grids, tunnel FET devices and biosensors. He was the General Chair of the IEEE-PEMC2016 conference and since 2012 he is Invited Full Professor of Burgas Free University, Bulgaria.

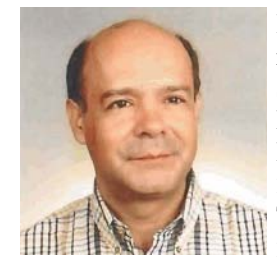

R. Melício, was born in Lisbon, Portugal, and received the MSc in 2004, from Instituto Superior Técnico, Lisbon, Portugal, received the $\mathrm{PhD}$ in 2010 from Universidade da Beira Interior, Portugal, received the Post-PhD in 2012 from Fundação para a Ciência e a Tecnologia, Lisbon, Portugal and Habilitation in 2014 from the Universidade de Évora, Portugal. $\mathrm{He}$ is member of IDMEC research laboratory and an Assistant Professor with Habilitation at Universidade de Évora. His research interests include: power electronics and its applications; power systems management and operation; renewable energies; smart grids. He is a senior member of the IEEE Industrial Electronics Society.

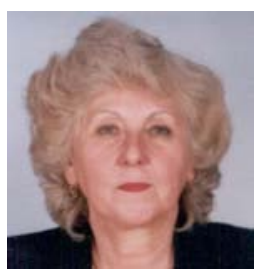

Anastassia Krusteva finished Moscow Institute of Energy, Russia in Electro technical Devices and obtained Ph.D. in the Technical University Sofia, Power Electronics Department. She has research and training experience in the field of Power electronics, Renewable Energy Sources and Distributed Energy Production, Modeling and optimization of RES inverters and its networks connections. She is participant and responsible for various EU contracts related to the energies topics. She was Vice Director of the Research and Development Sector, 1992 2008 and project leader in TUS R\&DS sins now. She has more of 95 publications including papers in scientific journals and conferences.

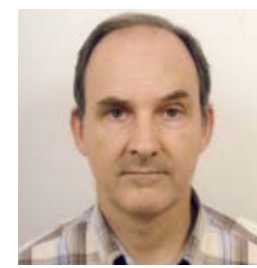

V. Fernão Pires, received the B.S. degree in Electrical Engineering from Institute Superior of Engineering of Lisbon, Portugal, in 1988 and the M.S. and Ph.D. Degrees in Electrical and Computer Engineering from Technical University of Lisbon, Portugal, in 1995 and 2000 , respectively. Since 1991 he is a member of the teaching staff at Electrical Engineering Department of Superior Technical School of Setúbal - Polytechnic Institute of Setúbal. Presently he is a Professor, teaching Power Electronics and Control of Power Converters. He is also researcher at Instituto de Engenharia de Sistemas e Computadores, Investigação e Desenvolvimento em Lisboa (INESC-ID). His present research interests include the areas of topologies and control of power converters. 